\title{
Effects of feeding corn silage, pelleted, ensiled, or pelleted and ensiled alfalfa on growth and carcass characteristics of lamb
}

\author{
F.L. Fluharty ${ }^{1 \#}$, H.N. Zerby ${ }^{2}$, G.D. Lowe ${ }^{1}$, D. D. Clevenger ${ }^{1}$ \& A.E. Relling ${ }^{1}$ \\ ${ }^{1}$ Department of Animal Sciences, The Ohio State University, 1680 Madison Ave. Wooster, OH 44691, USA \\ ${ }^{2}$ Department of Animal Sciences, The Ohio State University, 2029 Fyffe Rd., Columbus, OH 43210, USA
}

(Received 7 October 2016; Accepted 16 August 2017; First published online 14 September 2017)

Copyright resides with the authors in terms of the Creative Commons Attribution 4.0 South African License.
See: http://creativecommons.org/licenses/by/4.0/za
Condition of use: The user may copy, distribute, transmit and adapt the work, but must recognize the authors and the South African
Journal of Animal Science.

\begin{abstract}
Two experiments were conducted to evaluate the effects of corn silage (CS) and alfalfa (pelleted (AP), haylage $(\mathrm{AH})$, or combination $(\mathrm{APH})$ ) on lamb growth and carcass characteristics. The objective of Experiment 1 (Exp. 1) was to compare AH to CS in lamb feedlot diets on lamb growth and carcass characteristics. Eighty lambs were used in a 56 day experiment with a randomized complete block design. The objective of Experiment 2 (Exp. 2) was to determine the effects of alfalfa form, AP, AH or AHP, on animal performance and carcass characteristics. Seventy two lambs were used in an 82 day experiment with a randomized complete block design. In Exp. 1, lambs offered $\mathrm{AH}$ consumed $23.5 \%$ more feed on a daily basis than lambs offered CS. However, lambs fed CS gained weight $21.3 \%$ faster than lambs fed AH (259 versus $213 \mathrm{~g} /$ day, respectively). Additionally, lambs fed CS were $50.4 \%$ more efficient in converting feed to gain compared with lambs offered AH (0.173 versus $0.115 \mathrm{~kg}$ gain $/ \mathrm{kg}$ feed, respectively). In Exp. 2, AP resulted in a greater dry matter intake (DMI) and average daily gain (ADG), and fewer days on feed than with $\mathrm{AH}$. The combination of pellets + haylage resulted in a greater DMI, ADG, and fewer days on feed compared to $\mathrm{AH}$ alone. Therefore, there was an inverse relationship between both forage particle size and diet moisture content with DMI. There was no difference in daily efficiency of gain due to the form of alfalfa. Average daily gain, days on feed, and DMI are economically important criteria that differ due to the form of alfalfa even when feed efficiencies are similar.
\end{abstract}

Keywords: Fibre length, lamb performance, sheep

\#Corresponding author: fluharty.1@osu.edu

\section{Introduction}

Lamb feedlot diets are usually offered ad libitum. In the Midwest, corn is the least expensive energy source, and animals offered a high-concentrate diet ad libitum generally have greater ADG than animals grazed on grasses, legumes or fed dry pelleted legume diets (McClure et al., 2000; Murphy et al., 2003; Borton et al., 2005; Jaborek et al., 2017). However, lambs that graze or are fed ensiled or dry pelleted alfalfa accumulate less fat on a daily basis than lambs that are fed corn based diets (McClure et al., 2000; Murphy et al., 2003; Jaborek et al., 2017). Visceral organ weight increases due to the amount of forage consumed and the particle size of the forage. This increase in visceral organ size results in greater maintenance energy requirements of lambs grazing alfalfa, making the conversion of feed energy to protein gain less efficient (McClure et al., 2000). Nevertheless, consumers desire forage raised sheep products due to perceptions about health benefits of animals not raised using feed grains (Montossi et al., 2013). Furthermore, in an interview study with representatives of the retail, foodservice, and purveyor segments of the lamb meat industry in the United States, Hoffman et al. (2016) reported that the top three preference factors associated with a decision to purchase lamb were eating satisfaction, origin of the lamb indicating locally grown, and sheep raising that included being grass-fed, respectively. However, in the Midwest, Haemonchus contortus infestations that occur during the forage growing season make grazing management difficult and have negative health impacts on the grass-fed lambs (Campbell et al., 2017). Thus, information is required to determine the most efficient way to use harvested forages for lamb production.

Ensiled feeds may allow for growth of feedlot lambs without the management concerns of highconcentrate diets such as acidosis. In lamb feedlot diets, long-stem alfalfa does not mix well with the concentrate portion of the diet, and may result in sorting in the feed bunk. However, feeding ensiled or pelleted alfalfa should minimize digestive disorders, and blend well with the concentrate portion of a feedlot 
diet. Chopped alfalfa hay can vary in particle size and impact lamb growth (Al-Saiady et al., 2010), whereas ground, pelleted alfalfa more closely resembles a concentrate feed in terms of particle size. Hadjigeorgiou et al. (2003) fed three different lengths of forage, $13.29 \mathrm{~mm}, 7.26 \mathrm{~mm}$, and $0.69 \mathrm{~mm}$, to sheep and reported increased dry matter intake, reduced ruminal retention time, and improved digestive efficiency as particle size decreased. However, while differences in performance may exist, there is very little information in the literature comparing either the digestive characteristics or animal performance of sheep that are fed these types of diets.

The objectives of these studies were to compare alfalfa haylage to corn silage in lamb feedlot diets, and the effects of alfalfa pellets versus ensiled alfalfa in lamb feedlot diets on animal growth and carcass composition. The hypotheses were that corn silage would result in greater lamb performance compared with alfalfa haylage, and that pelleted alfalfa would result in a greater feed intake, and greater ADG compared with alfalfa haylage, without an increase in carcass fat.

\section{Materials and Methods}

All animal procedures were approved by the Agricultural Animal Care and Use Committee of The Ohio State University and followed guidelines recommended in the Guide for the Care and Use of Agricultural Animals in Agricultural Research and Teaching (FASS, 1998).

\section{Experiment 1}

Eighty Columbia $x$ Suffolk ewe lambs (initial body weight $51.9 \pm 0.4 \mathrm{~kg}$ ) were used in a randomized complete block experiment to determine the effects of alfalfa haylage versus corn silage on animal performance and carcass characteristics. The experiment averaged 56 days in duration for the lambs fed alfalfa haylage and 52 days duration for the lambs fed corn silage. The lambs originated from a ranch in Montrose, Colorado and were transported by truck approximately 2,545 kilometres to the OARDC sheep feedlot in Wooster, Ohio.

There were four blocks of lambs, based on body weight. There were ten lambs per replicate pen and four replicate pens in each of the two treatments. The pens were $3.0 \times 4.9 \mathrm{~m}$ with $3.0 \mathrm{~m}$ of bunk space, or $29.7 \mathrm{~cm}$ per lamb. All pens were constructed using expanded metal floors, with metal gates on three sides and a wooden fence line feed bunk on the fourth side. Each pen had an automatic water cup so that water was available at all times.

Diets were formulated to meet the dietary nutrient requirements of lambs (NRC, 1985), and to provide equal concentrations of crude protein (CP), vitamins, ammonium chloride, and lasalocid across treatments (Table 1). The concentration of phosphorus (P) was held constant at $0.4 \%$ across diets. However, because of the high concentration of calcium (Ca) in alfalfa (1.52\% on a dry matter (DM) basis), and the potential negative impact on diet palatability of increasing the level of supplemental $\mathrm{Ca}$ in diets containing corn silage, the concentration of $\mathrm{Ca}$ differed between diets.

Feed samples $(100 \mathrm{~g})$ were collected every $14 \mathrm{~d}$ throughout the experiment, dried in a forced air oven at $55^{\circ} \mathrm{C}$, ground to pass a $1-\mathrm{mm}$ screen, and analyzed for DM (AOAC, 1984). Upon arrival at the feedlot, the lambs were provided long-stem alfalfa hay and had access to water troughs containing an electrolyte solution. Following an 18 hour rest period, the lambs were individually weighed, ear tagged, and vaccinated against Clostridium perfringens Types $\mathrm{C}$ and $\mathrm{D}$, and Tetanus, with a second vaccine against Clostridium perfringens Types $C$ and $D$, and Tetanus given $14 \mathrm{~d}$ later. Feed offered and feed refused were weighed daily in each pen prior to feeding at $0830 \mathrm{hrs}$. Because sorting was expected, and to prevent feed spoilage, feed refusals were not allowed to remain in the feed bunk for more than 1 day before they were discarded. This was done because nutrient content of the diet available to the lambs could differ substantially among the diet groups if sorting occurred. Pens of lambs never had their intake increased or decreased by more than $10 \%$ of the previous day's intake. Initial and final weights of the lambs were determined using the average of weights taken on two consecutive days, and 14 day intermediate weights were taken prior to feeding at 0800 . Average daily gain (ADG), dry matter intake (DMI), feed efficiency (gain/feed), and days required to reach slaughter weight were determined for all lambs. Lambs were removed from the trial, on a pen basis, as each pen reached the predetermined terminal weight range of 63.5 to 65.8 kilograms. Lambs were slaughtered at a commercial abattoir. Two pens containing 10 lambs per pen were harvested for carcass data in each treatment group. Chilled carcass weights were determined $48 \mathrm{~h}$ after slaughter, then back fat and loin eye area were measured, and internal fat was estimated

Statistical analysis was performed using the MIXED procedure of SAS (2008) for a randomized complete block experiment that was blocked by animal weight. Pen was used as the experimental unit for lamb performance and carcass data. Data were analysed using a model that included effects due to diet and size block. Treatment means were compared using Fisher's LSD, using the PDIFF statement of SAS 9.3 
(2008) when protected by a significant $(P<0.05) \mathrm{F}$-value. The residual mean square was used as the error term.

Table 1 Composition of diets in Experiment 1 to determine effects of corn silage or alfalfa haylage on growth, feed efficiency, and carcass characteristics of lambs

\begin{tabular}{|c|c|c|}
\hline \multirow{2}{*}{ Item } & Corn silage & Alfalfa haylage \\
\hline & \multicolumn{2}{|c|}{$\%$, Dry matter basis } \\
\hline Corn silage & 70.00 & - \\
\hline Alfalfa haylage & - & 70.00 \\
\hline Ground corn & 11.47 & 20.27 \\
\hline Soybean meal & 16.80 & 7.60 \\
\hline Urea & 0.30 & 0.30 \\
\hline Dicalcium phosphate & 0.20 & - \\
\hline Monosodium phosphate & - & 0.60 \\
\hline Trace mineral salt ${ }^{1}$ & 0.45 & 0.45 \\
\hline Vitamin A, 30,000 IU/g & 0.01 & 0.01 \\
\hline Vitamin D, 3,000 IU/g & 0.01 & 0.01 \\
\hline Vitamin E, $44 \mathrm{IU} / \mathrm{g}$ & 0.05 & 0.05 \\
\hline Selenium, 201 ppm & 0.09 & 0.09 \\
\hline Dynamate $^{2}$ & 0.20 & 0.20 \\
\hline Ammonium chloride & 0.40 & 0.40 \\
\hline Lasalocid $^{3}, 150 \mathrm{~g} / \mathrm{kg}$ & 0.022 & 0.022 \\
\hline \multicolumn{3}{|l|}{ Calculated composition } \\
\hline Crude protein, \% & 18.01 & 18.01 \\
\hline Calcium, \% & 0.67 & 1.09 \\
\hline Phosphorus, \% & 0.44 & 0.43 \\
\hline $\mathrm{NEm}, \mathrm{Mcal} / \mathrm{kg}$ & 1.75 & 1.47 \\
\hline $\mathrm{NEg}, \mathrm{Mcal} / \mathrm{kg}$ & 1.14 & 0.89 \\
\hline
\end{tabular}

\footnotetext{
${ }^{1}$ Contained $>93 \% \mathrm{NaCl}, 0.35 \% \mathrm{Zn}, 0.28 \% \mathrm{Mn}, 0.175 \% \mathrm{Fe}, 0.035 \% \mathrm{Cu}, 0.007 \% \mathrm{I}$, and $0.007 \%$ Co.

2 Magnesium sulfate and potassium sulfate contained $22 \%$ S, $18 \% \mathrm{~K}, 11 \% \mathrm{Mg}$ (International Minerals and Chemical Co., Terre Haute, IN).

${ }^{3}$ lasalocid (Bovatec; Alpharma Animal Health, Bridgewater, NJ).
}

\section{Experiment 2}

Seventy-two Rambouillet $x$ Hampshire lambs (initial weight $52.4 \pm 0.2 \mathrm{~kg}$ ) were used in a randomized complete block experiment to determine the effects of alfalfa form and combinations on animal performance and carcass characteristics. There were twenty-four wethers and forty-eight ewes used in the experiment. The lambs originated from a ranch in Savery, Wyoming and were transported by truck approximately 2,544 kilometers to the OARDC sheep feedlot in Wooster, Ohio.

Three diets were fed (Table 2). Diets were formulated to meet the dietary nutrient requirements of lambs (NRC, 1985), and to provide equal concentrations of vitamins, ammonium chloride, and lasalocid across treatments. Diets were formulated to contain $70 \%$ alfalfa on a dry matter basis. In the first diet, the alfalfa was fed as a dried, pelleted alfalfa. In the second diet, the alfalfa was fed as an alfalfa haylage. In the third diet, half of the alfalfa was fed in the pelleted form and half of the alfalfa was fed in the haylage form.

There were two blocks of lambs, based on lamb sex and weight. All blocks had four lambs per replicate pen, and there were six replicate pens per each of the three treatments. The pens were $1.5 \times 4.9 \mathrm{~m}$ with $1.5 \mathrm{~m}$ of bunk space. All pens were constructed using expanded metal floors, with metal gates on three sides and a wooden fence line feed bunk on the fourth side. Each pen had an automatic water cup so that water was available at all times. 
Table 2 Composition of diets in Experiment 2 to determine the effects of form of alfalfa on growth, feed efficiency, and carcass characteristics of lambs

\begin{tabular}{|c|c|c|c|}
\hline \multirow{2}{*}{ Item } & Alfalfa pellets & Alfalfa haylage & Alfalfa combination \\
\hline & \multicolumn{3}{|c|}{$\%$, Dry matter basis } \\
\hline Pelleted alfalfa & 70.00 & - & 35 \\
\hline Alfalfa haylage & - & 70.00 & 35 \\
\hline Ground corn & 20.268 & 20.268 & 20.268 \\
\hline Soybean meal & 7.60 & 7.60 & 7.60 \\
\hline Urea & 0.30 & 0.30 & 0.30 \\
\hline Monosodium phosphate & 0.60 & 0.60 & 0.60 \\
\hline Trace mineral salt ${ }^{1}$ & 0.45 & 0.45 & 0.45 \\
\hline Vitamin A, 30,000 IU/g & 0.01 & 0.01 & 0.01 \\
\hline Vitamin D, 3,000 IU/g & 0.01 & 0.01 & 0.01 \\
\hline Vitamin E, $44 \mathrm{lU} / \mathrm{g}$ & 0.05 & 0.05 & 0.05 \\
\hline Selenium, 201 ppm & 0.09 & 0.09 & 0.09 \\
\hline Ammonium chloride & 0.40 & 0.40 & 0.40 \\
\hline Lasalocid $^{2}, 150 \mathrm{~g} / \mathrm{kg}$ & 0.022 & 0.022 & 0.022 \\
\hline Dynamate $^{3}$ & 0.20 & 0.20 & 0.20 \\
\hline \multicolumn{4}{|l|}{ Calculated composition } \\
\hline Crude protein, \% & 20.40 & 18.02 & 19.21 \\
\hline Calcium, \% & 1.09 & 1.09 & 1.09 \\
\hline Phosphorus, \% & 0.43 & 0.43 & 0.43 \\
\hline $\mathrm{NE}_{\mathrm{m}}, \mathrm{Mcal} / \mathrm{kg}$ & 1.54 & 1.47 & 1.50 \\
\hline $\mathrm{NE}_{g}, \mathrm{Mcal} / \mathrm{kg}$ & 0.95 & 0.89 & 0.92 \\
\hline
\end{tabular}

\footnotetext{
${ }^{1}$ Contained $>93 \% \mathrm{NaCl}, .35 \% \mathrm{Zn}, .28 \% \mathrm{Mn}, .175 \% \mathrm{Fe}, .035 \% \mathrm{Cu}, .007 \% \mathrm{I}$, and $.007 \% \mathrm{Co}$.

${ }^{12}$ lasalocid (Bovatec; Alpharma Animal Health, Bridgewater, $\left.\mathrm{NJ}\right)$.

${ }^{3}$ Magnesium sulfate and potassium sulfate contained $22 \% \mathrm{~S}, 18 \% \mathrm{~K}, 11 \% \mathrm{Mg}$, (International Minerals and Chemical Co., Terre Haute, IN).
}

Feed samples $(100 \mathrm{~g})$ were collected every $14 \mathrm{~d}$ throughout the experiment and composited for analysis. Feed samples were dried in a forced air oven at $55^{\circ} \mathrm{C}$, ground to pass a $2-\mathrm{mm}$ screen, and analyzed for DM (AOAC, 1984). Lambs were individually weighed, ear tagged, and vaccinated against internal and external parasites with injectable Ivermectin. Feed offered and feed refused were weighed daily in each pen prior to refeeding at 0830 . Because sorting was expected, feed was not allowed to remain in the feed bunk for more than 1 day before it was discarded. This was done because nutrient content of the diet available to the lambs could differ substantially among the diet groups if sorting occurred. Pens of lambs never had their intake increased or decreased by more than $10 \%$ of the previous day's intake. Initial and final weights of the lambs were determined using the average of weights taken on two consecutive days, and 14 day intermediate weights were taken prior to feeding at 0800 . Average daily gain, DMI, feed efficiency (kg gain $/ \mathrm{kg}$ feed), and days required to reach slaughter weight were determined for all lambs. Lambs were removed from the trial, on a pen basis, as each pen reached the predetermined terminal weight range of 63.5 to $68.0 \mathrm{~kg}$. Lambs were slaughtered at a commercial abattoir. Chilled carcass weights were determined $48 \mathrm{~h}$ after slaughter, and back fat and loin eye area were measured, and internal fat was estimated.

Statistical analysis was performed using the MIXED procedure of SAS (2008) for a randomized complete block experiment that was blocked by pen size. Performance data for the total trial were analyzed using a model that included effects due to diet, sex and size block. Pen was used as the experimental unit for lamb performance and carcass data. Carcass data were analyzed using a model that included effects due to diet, sex and size block. Treatment means were compared with Fisher's protected LSD using the PDIFF statement of SAS 9.3 (2008) when protected by a significant $(P<0.05)$ F-value. The residual mean square was used as the error term. 


\section{Results and Discussion}

\section{Experiment 1}

The effects of alfalfa haylage versus corn silage on lamb performance are shown in Table 3. Lambs offered alfalfa haylage consumed $23 \%$ more $(P<0.01)$ feed on a daily basis than lambs offered corn silage (1.85 versus $1.50 \mathrm{~kg} / \mathrm{d}$, respectively). However, lambs fed corn silage gained $21.6 \%$ faster $(P<0.01)$ than lambs fed alfalfa haylage (259 versus $213 \mathrm{~g} / \mathrm{d}$, respectively). Additionally, lambs fed corn silage were $50.4 \%$ more efficient in converting feed to gain compared with lambs offered alfalfa haylage $(0.173$ versus $0.115 \mathrm{~kg}$ gain $/ \mathrm{kg}$ feed, respectively). This percentage difference in efficiency of gain with corn silage versus alfalfa haylage is very close to the $51.5 \%$ difference in net energy available for gain (NEg) concentrations reported for well-eared corn silage $(1.03 \mathrm{Mcal} / \mathrm{kg})$ and alfalfa silage between $30-50 \%$ dry matter $(0.68 \mathrm{Mcal} / \mathrm{kg})$ (NRC, 1985). As a result of the difference in efficiency of gain, lambs fed corn silage required $77.6 \mathrm{~kg}$ of feed to reach their market weight versus $102.5 \mathrm{~kg}$ of feed for the lambs fed alfalfa haylage $(P<0.01)$.

Table 3 Means and SEM of the effects of alfalfa haylage versus corn silage on lamb performance

\begin{tabular}{lcccr}
\hline Item & Alfalfa haylage & Corn silage & SEM & P Value \\
\hline No. of pens & 4 & 4 & & \\
No. of lambs & 40 & 40 & & \\
Initial wt, $\mathrm{kg}$ & 52.38 & 51.47 & 0.42 & 0.22 \\
Final wt, $\mathrm{kg}$ & 64.17 & 64.90 & 0.33 & 0.22 \\
DMl, $\mathrm{kg} / \mathrm{d}$ & 1.85 & 1.50 & 0.01 & $<0.01$ \\
Days on test & 55.5 & 52.0 & 1.4 & 0.18 \\
ADG, g/d & 213 & 259 & 5.0 & $<0.01$ \\
G/F, $\mathrm{kg} / \mathrm{kg}$ & 0.115 & 0.173 & 0.004 & $<0.01$ \\
Total DMl, kg & 102.5 & 77.6 & 1.4 & $<0.01$ \\
\hline
\end{tabular}

The effects of diet on carcass characteristics are shown in Table 4. There were no differences $(P$ $>0.10$ ) in hot carcass weight or dressing percentage between lambs fed corn silage or lambs offered alfalfa haylage (33.9 $\mathrm{kg}$ and $52 \%$ versus $32.4 \mathrm{~kg}$ and $49.7 \%$, respectively). Fluharty and McClure (1997) reported that lambs fed high-concentrate diets at restricted intakes had less visceral organ mass than lambs fed the same high-concentrate diets offered ad libitum, but that dressing percentage was not different due to increased visceral fat in the lambs offered feed ad libitum. In the present study, there were no differences $(P$ $>0.10)$ in backfat and yield grade between lambs fed corn silage or lambs fed alfalfa haylage $(0.66 \mathrm{~cm}$ and 3.5 versus $0.55 \mathrm{~cm}$ and 3.3, respectively) even though the lambs offered alfalfa haylage consumed $23.6 \%$ more feed on a daily basis. However, based on the efficiency of gain in the present study, the alfalfa haylage was probably not as digestible as the corn silage. This difference in digestibility, coupled with the greater energy density of corn silage compared with alfalfa haylage, resulted in more total energy available for gain with the lambs fed corn silage.

\section{Experiment 2}

The effects of form of alfalfa on lamb performance are shown in Table 5. Pelleted alfalfa resulted in a greater $(P<0.01) \mathrm{DMl}$ compared with pellets + haylage, or haylage alone. The combination of pellets + haylage resulted in a greater $(P<0.01) \mathrm{DMI}$ compared to haylage alone. Therefore, there was an inverse relationship between both forage particle size and diet moisture content with dry matter intake. It is probable that smaller forage particles spend less time in the rumen and reticulum compared with larger particles that may need to be regurgitated and remasticated before they can pass out of the reticulum. The smaller particles with the ground, pelleted alfalfa compared with alfalfa haylage allow for more surface area for ruminal bacteria to attach and digest the feed particles. Hintz et al. (1999) reported that mechanical maceration of alfalfa resulted in more surface area being available for degradation, allowing for a more rapid rate of digestion, a faster rate of passage of indigestible components from the rumen allowing for an increase in feed intake, and the possibility that these factors allowed for an increase in propionate production due to a faster rate of digestion, and an increased rate of passage of indigestible components. 
Table 4 Mean and SEM of the effects of alfalfa haylage versus corn silage on lamb carcass characteristics

\begin{tabular}{|c|c|c|c|c|}
\hline Item & Alfalfa haylage & Corn silage & SEM & $P$ value \\
\hline No. of pens & 2 & 2 & & \\
\hline No. of lambs & 20 & 20 & & \\
\hline Final wt, kg & 65.28 & 65.22 & 0.14 & 0.79 \\
\hline $\mathrm{HCW}, \mathrm{kg}$ & 32.43 & 33.92 & 0.83 & 0.42 \\
\hline Dressing \% & 49.7 & 52.0 & 1.2 & 0.39 \\
\hline Fat depth, cm & 0.55 & 0.66 & 0.04 & 0.32 \\
\hline Leg conformation ${ }^{1}$ & 10.8 & 11.1 & 0.2 & 0.39 \\
\hline Quality grade $^{1}$ & 11.2 & 11.1 & 0.1 & 0.50 \\
\hline $\mathrm{KPH}$ fat, \% & 3.3 & 3.5 & 0.1 & 0.50 \\
\hline Yield grade $^{2}$ & 3.4 & 3.7 & 0.1 & 0.37 \\
\hline L. dorsi area, $\mathrm{cm}^{2}$ & 18.0 & 18.0 & 0.9 & 0.98 \\
\hline
\end{tabular}

${ }^{1} 10=$ Choice $^{-}, 11=$ Choice $^{0}, 12=$ Choice $^{+}$.

$21.66-(.05 \times$ leg conformation $)+(.25 \times \% \mathrm{KPH})+(6.66 \times$ fat depth, inches $)$.

A faster rate of digestion allows an animal to consume more feed, as there is less undigested feed taking up space in the rumen. The rate, and extent, of fibre digestion in the rumen is controlled by the surface area that is available for the fibre digesting bacteria to attach. With unprocessed forages, the large size of mature forage reduces the energy available to the animal, because for digestion to occur, the microorganisms in the rumen must first be associated with the forage, and then attach to the forage. Furthermore, digestion of the forage by the bacteria normally occurs from the inside of the forage to the outer layers, with the mesophyll and phloem being degraded prior to the outer layers, primarily due to initial colonization of fiber being done by organisms possessing enzymes that attack the easily available side chains of complex plant polysaccharides and not the more recalcitrant main chains, especially cellulose (Brulc et al., 2009). Earlier work found that limitations to the speed at which digestion occurs include the physical and chemical properties of the forage, the moisture level of the forage, time for penetration of the waxes and cuticle layer, and the extent of lignification (Varga \& Kolver, 1997). In the current study, the drier feed particles with the pelleted alfalfa compared to alfalfa haylage would mean that the pelleted alfalfa was more energy dense (less space taken up with water). These two factors resulted in lambs consuming pelleted alfalfa having a $48.9 \%$ greater $(P<0.01)$ ADG compared with lambs consuming alfalfa haylage $(277$ versus $186 \mathrm{~g} / \mathrm{d}$, respectively). Lambs consuming the pelleted alfalfa + haylage diet had a $33.9 \%$ increase $(P<0.01)$ in ADG compared with the haylage fed lambs $(249$ versus $186 \mathrm{~g} / \mathrm{d}$, respectively). Because the lambs were taken to similar terminal weights, the increase in ADG with alfalfa pellets versus alfalfa haylage resulted in lambs fed the pelleted alfalfa requiring 53.8 days to reach their slaughter weight compared with 60.8 days for lambs fed the alfalfa pellet + haylage diet, and 81.8 days for lambs fed the alfalfa haylage diet alone. These results are in contrast to those of Yang et al. (2002) who reported that increased forage particle size resulted in improved fibre and $\mathrm{N}$ digestibility in dairy cows fed a $60 \%$ barley and $40 \%$ alfalfa diet. However, they are in agreement with the results of Al-Saiady et al. (2010) that while NDF and ADF digestibility may be lower for smaller particle length alfalfa fed to growing lambs, the smaller particle size may lead to more efficient growth and improved carcass weight and percent protein and fat compared with alfalfa fed at longer chopped lengths. What this shows is that differences in species, and grain levels in diets, make comparisons difficult due to inherent difference in rumen $\mathrm{pH}$, feed intake level as a percentage of body weight, rate of passage, and retention time. Thus, when determining the outcome of a sheep feeding study, the most appropriate comparisons are other experiments using sheep. There were no differences $(P>0.06)$ in feed efficiency or total DMI due to form of alfalfa.

The effects of form of alfalfa on lamb carcass characteristics are shown in Table 6. There were no differences in hot carcass weight (HCW), loin eye area, or back fat depth due to form of alfalfa. However, lambs fed pelleted alfalfa approached significance $(P=0.06)$ in dressing percentage compared to lambs fed alfalfa haylage, with the lambs fed the combination diet being intermediate, and not different from either of the other two diets. The most likely reason for this would be increased undigested feed particles and associated increases in ruminal water with diets containing longer particles of forage. 
Table 5 Mean and SEM of the effects of form of alfalfa on lamb performance

\begin{tabular}{|c|c|c|c|c|c|}
\hline \multirow{2}{*}{ Item } & \multicolumn{3}{|c|}{ Pellets + } & \multirow[b]{2}{*}{ SEM } & \multirow[b]{2}{*}{ P Value } \\
\hline & Pellets & Haylage & Haylage & & \\
\hline No. pens & 6 & 6 & 6 & & \\
\hline No. lambs & 24 & 24 & 24 & & \\
\hline Initial wt, kg & 52.52 & 52.38 & 52.52 & 0.04 & 0.69 \\
\hline Final wt, kg & 66.98 & 67.45 & 67.41 & 0.58 & 0.81 \\
\hline Days on test & $53.8^{a}$ & $60.8^{a}$ & $81.8^{\mathrm{b}}$ & 3.0 & $<0.01$ \\
\hline DMI, kg/d & $2.33^{a}$ & $2.01^{b}$ & $1.66^{c}$ & 0.05 & $<0.01$ \\
\hline$A D G, g / d$ & $277^{a}$ & $249^{a}$ & $186^{\mathrm{b}}$ & 9.0 & $<0.01$ \\
\hline $\mathrm{G} / \mathrm{F}, \mathrm{kg} / \mathrm{kg}$ & 0.118 & 0.125 & 0.111 & 0.004 & 0.07 \\
\hline Total DMI, kg & 124.6 & 121.4 & 136.1 & 5.8 & 0.20 \\
\hline
\end{tabular}

DMI = Dry Matter Intake, ADG = Average daily gain,

Usually, when high concentrate diets are fed (Fluharty \& McClure, 1997), or when high-concentrate diets are compared with alfalfa (Fluharty et al., 1999), increases in DMI result in increases in visceral organ mass and gut contents with resulting decreases in dressing percentage. However, when forages are compared, reductions in particle size, with resulting reductions in ruminal retention time may override increased DMI when compared with diets containing long forage particles, or relatively indigestible forage particles.

Table 6 Mean and SEM of the effects of form of alfalfa on lamb carcass characteristics

\begin{tabular}{|c|c|c|c|c|c|}
\hline \multirow{2}{*}{ Item } & \multicolumn{3}{|c|}{ Pellets + } & \multirow[b]{2}{*}{ SEM } & \multirow[b]{2}{*}{ P Value } \\
\hline & Pellets & Haylage & Haylage & & \\
\hline No. pens & 6 & 6 & 6 & & \\
\hline No. lambs & 24 & 24 & 24 & & \\
\hline Final wt, kg & 66.98 & 67.45 & 67.41 & 0.58 & 0.81 \\
\hline $\mathrm{HCW}, \mathrm{kg}$ & 33.28 & 33.18 & 32.52 & 0.50 & 0.51 \\
\hline Dressing \% & $49.6^{\mathrm{a}}$ & $49.2^{\mathrm{ab}}$ & $48.2^{b}$ & 0.4 & 0.06 \\
\hline Fat depth, cm & 0.58 & 0.56 & 0.53 & 0.04 & 0.71 \\
\hline Leg conformation ${ }^{1}$ & 11.3 & 11.1 & 10.8 & 0.1 & 0.09 \\
\hline Quality grade $^{1}$ & 11.5 & 11.2 & 11.2 & 0.1 & 0.11 \\
\hline $\mathrm{KPH}$ fat, \% & 3.5 & 3.4 & 3.5 & 0.1 & 0.56 \\
\hline Yield grade $^{2}$ & 3.5 & 3.4 & 3.4 & 0.1 & 0.76 \\
\hline $\mathrm{L}$ dorsi area, $\mathrm{cm}^{2}$ & 17.9 & 18.4 & 17.5 & 0.5 & 0.51 \\
\hline
\end{tabular}

$10=$ Choice-, $11=$ choice $^{0}, 12=$ choice $^{+}$.

$21.66-(0.05 \times$ leg conformation $)+(.25 \times \% \mathrm{KPH})+(6.66 \times$ adjusted fat depth,inches $)$.

\section{Conclusions}

Corn silage and alfalfa haylage resulted in growth rates between 259 and $213 \mathrm{~g} /$ day, respectively. However, even at relatively slow growth rates with forage based diets, differences in dietary energy density corresponded with differences in net energy available for gain. In feedlot situations, processed forages can be used to effectively produce large, lean lamb carcasses. Alfalfa particle size and forage moisture content greatly affect dry matter intake and animal performance, even when the forage is one species of similar maturity. Average daily gain, days on feed and dry matter intake are economically important criteria that differ due to form of alfalfa even when feed efficiencies are similar. Additionally, lamb marketing could be 
spread out over a longer period of time, reducing the seasonality of lamb, by altering the form of forage fed in forage-based feedlot situations.

\section{Acknowledgements}

Authors acknowledge the sheep farm unit crew for their help in data collection.

\section{Authors' Contributions}

FLF: conceived the idea and project management. HNZ: conceived the idea and carcass characteristics data collection and analysis. GDL statistical analysis. DDC performance data collection and analysis. AER. Discussed results, Data analysis and manuscript preparation.

\section{Conflict of Interest Declaration}

Authors declare that they have no conflict of interest.

\section{References}

Al-Saiady, M.Y., Abouheif, M.A., Aziz Makkawi, A., Ibrahim, H.A. \& Al-Owaimer, A.N., 2010. Impact of particle length of alfalfa hay in the diet of growing lambs on performance, digestion and carcass characteristics. Asian-Aust. J. Anim. Sci. 23,475-482.

AOAC, 1984. Official methods of analysis (14th Ed.). Association of Official Analytical Chemists, Washington, DC.

Borton, R.J., Loerch, S.C., McClure, K.E. \& Wulf, D.M., 2005. Characteristics of lambs fed concentrates or grazed on ryegrass to traditional or heavy slaughter weights. II. Wholesale cuts and tissue accretion.

Brulc, Jennifer M., Antonopoulosb, D.A., Berg Miller, M.E., Wilson, M.K., Yannarell, A.C., Dinsdale, E.A., Edwards, R.E., Frank, E.D., Emerson, J.B., Wacklin, P., Coutinho, P.M., Henrissat,B., Nelso, K.E. \& White, B.A.,2009. Genecentric metagenomics of the fiber-adherent bovine rumen microbiome reveals forage specific glycoside hydrolases. Proc. Natl. Acad. Sci. U S A. 106, 1948-1953.

Campbell, B. N., Pullin, A.N., Pairis-Garcia, M.D. \& Fluharty, F.L., 2017. The effects of alternative weaning strategies on lamb health and performance. Small Ruminant Res. (In Press). DOI: 10.1016/j.smallrumres.2017.09.006

Federation of Animal Science Societies., 1998. Guide for the Care and Use of Agricultural Animals in Agricultural Research and Teaching. Fed. Anim. Sci. Soc., Savoy, IL.

Fluharty, F.L. \& McClure, K.E., 1997. Effects of dietary energy intake and protein concentration on performance and visceral organ mass in lambs. J. Anim. Sci. 75,604-610.

Fluharty, F.L., McClure, K.E., Solomon, M.B., Clevenger, D.D. \& Lowe, G.D., 1999. Energy source and ionophore supplementation effects on lamb growth, carcass characteristics, visceral organ mass, diet digestibility, and nitrogen metabolism. J. Anim. Sci. 77,816-823.

Hadjigeorgiou, I.E., Gordon, I.J. \& Milne, J.A., 2003. Intake, digestion and selection of roughage with different staple lengths by sheep and goats. Small Rumin Res. 47, 117-132.

Hintz, R.W., Koegel, R G., Kraus, T.J. \& Mertens, D.R., 1999. Mechanical maceration of alfalfa. J. Anim. Sci. 77,187193.

Hoffman, T.W., Belk, K.E., Woerner, D.R., Tatum, J.D., Delmore, R.J., Peel, R.K., LeValley, S.B., Pendell, D.L., Zerby, H.N., English, L.F., Moeller, S.J. \& Fluharty, F.L., 2016. Preferences associated with American lamb quality in retail and foodservice markets. Meat Sci. 112,138.

Jaborek, J. R., Zerby, H. N., Moeller, S.J. \& Fluharty, F.L. 2017. Effect of energy source and level, and sex on growth, performance, and carcass characteristics of lambs. Small Rumin Res. 151, 117-123.

McClure, K. E., Solomon, M.B. \& Loerch, S.C., 2000. Body weight and tissue gain in lambs fed an all-concentrate diet and implanted with trenbolone acetate or grazed on alfalfa. J. Anim. Sci. 78,1117-1124.

Montossi, F., Font-i-Furnols, M., del Campo, M., San Julián, R. Brito, G. \& Sañudo, C. 2013. Sustainable sheep production and consumer preference trends, Compatibilities, contradictions, and unresolved dilemmas. Meat Sci. 95, 772-789.

Murphy, M. A., Zerby, H.N. \& Fluharty, F.L, 2003. The effects of energy source and ionophore supplementation on lamb growth, carcass characteristics and tenderness. Sheep Goat Res. J. 18,89-95.

NRC., 1985. Nutrient Requirements of Sheep (6th Ed.). National Academy Press, Washington, DC.

SAS/STAT.,1988. SAS/STAT User's Guide, Statistics. SAS Inst., Inc., Cary, NC.

Varga, G.A. \& Kolver, E.S., 1997. Microbial and animal limitations to fiber digestion and utilization. J. Nutr. 127, 819S823S.

Yang, W.Z., Beauchemin, K.A. \& Rode, M.L., 2002. Effects of particle size of alfalfa-based dairy cow diets on site and extent of digestion. J. Dairy Sci. 85,1958-1968. 